\title{
An investigation into the variation of human contrast sensitivity with age and ocular pathology
}

\author{
KEITH ARUNDALE \\ From the Department of Visual Science, Institute of Ophthalmology, London
}

SUMMARY The contrast sensitivities to sine-wave grating stimuli were measured for 36 observers with ages in the range 8 to 67 years. Thirty-one observers had normal, healthy vision while 4 were suffering from diabetic retinopathy and 1 had early lens opacities and macular degeneration. The younger members of the group with normal vision were less sensitive to low spatial frequencies and the older members were less sensitive to high spatial frequencies than the middle-aged observers. The 5 observers with pathological conditions were less sensitive to most grating stimuli than those with normal vision.

Grating contrast sensitivity tests have been used to study the physiology of the visual system for some time (Schade, 1956; Campbell and Green, 1965) and are increasingly used to study ophthalmological and neural disorders (e.g., Bodis-Wollner and Diamond, 1976; Hess and Garner, 1977). Unlike the Snellen letter acuity test, which establishes visual acuity in terms of the smallest recognisable object presented at $100 \%$ contrast, the grating test allows the specification of an observer's sensitivity to larger targets of lower contrast. The graphic representation of spatial contrast sensitivity as a function of the spatial frequency of a sinusoidal grating is called the contrast sensitivity function (CSF). The shape of the CSF is known to be affected by several observer variables, such as pupil diameter and the refractive power of the eye (Campbell and Green, 1965), but its variation with age for a large number of different observers has not been previously reported. This paper presents the results of an investigation into the variation of the CSF with age for 31 naïve observers with normal vision and also illustrates the deviation of the CSF away from normal in the case of 5 observers with ophthalmological disorders.

\section{Method}

The contrast thresholds for vertical sinusoidal gratings of 8 different spatial frequencies were measured for 36 naïve observers (42 eyes). The observers were examined ophthalmologically prior

Address for reprints: Mr Keith Arundale, 12 Beverley Road, London W4 2LP to determining their contrast thresholds and were either corrected for refractive error or wore their normal corrective lenses if these had been recently prescribed. Thirty-one observers (33 eyes) had normal, healthy vision, while 4 were suffering from bilateral diabetic retinopathy ( 7 eyes) and 1 had early lens opacities and macular degeneration in both eyes. The ages of the observers ranged from 8 to 67 years.

The gratings were electronically generated on the screen of a monochrome television monitor (Melford Electronics DU1/20, 625 lines, $50 \mathrm{~Hz}, 2: 1$ interlaced, P4 phosphor). The experiments were performed under photopic conditions with the mean luminance of the gratings constant at $100 \mathrm{~cd} /$ $\mathrm{m}^{2}$. Observers viewed the gratings from 2 distances, $115 \mathrm{~cm}$ and $345 \mathrm{~cm}$, so that a sufficient range of spatial frequencies could be selected without too few bars at low frequencies. The television screen subtended $18^{\circ} \times 15^{\circ}$ and $6^{\circ} \times 5^{\circ}$ respectively at these distances. To minimise fading at low spatial frequencies and the generation of after-images the gratings were continuously reversed at the rate of $1 \mathrm{cycle} / \mathrm{s}$ and observers were instructed to fixate a small spot in the centre of the screen. The observers viewed the gratings monocularly with the fellow eye occluded.

At each spatial frequency the contrast of the grating was reduced by the experimenter by means of a potentiometer until the observer indicated that the grating had just disappeared. Threshold was determined as the mean of 5 independent decisions, and the order of presentation of the frequencies was randomised. Contrast is here defined as $\left(\mathrm{L}_{\max }\right.$ $\left.\mathbf{L}_{\min }\right) /\left(\mathbf{L}_{\max }+\mathbf{L}_{\min }\right)$ where $\mathbf{L}_{\max }$ and $\mathbf{L}_{\min }$ are the 


\begin{tabular}{llllll}
\hline $\begin{array}{l}\text { Age range } \\
\text { (years) }\end{array}$ & $\begin{array}{l}\text { Mean age } \\
\text { (years) }\end{array}$ & $\begin{array}{l}\text { Number of } \\
\text { eyes tested }\end{array}$ & $\begin{array}{l}\text { Mean } \\
\text { Snellen } \\
\text { acuity }\end{array}$ & $\begin{array}{l}\text { Mean pupil } \\
\text { diam (mm) }\end{array}$ \\
\hline$(---)$ & $8-15$ & 13 & 3 & 0.8 & 6.3 \\
$(--)$ & $18-39$ & 23 & 25 & 1.2 & 5.4 \\
$(\cdots \cdots)$. & $45-66$ & 58 & 5 & 0.7 & 3.8 \\
\hline
\end{tabular}

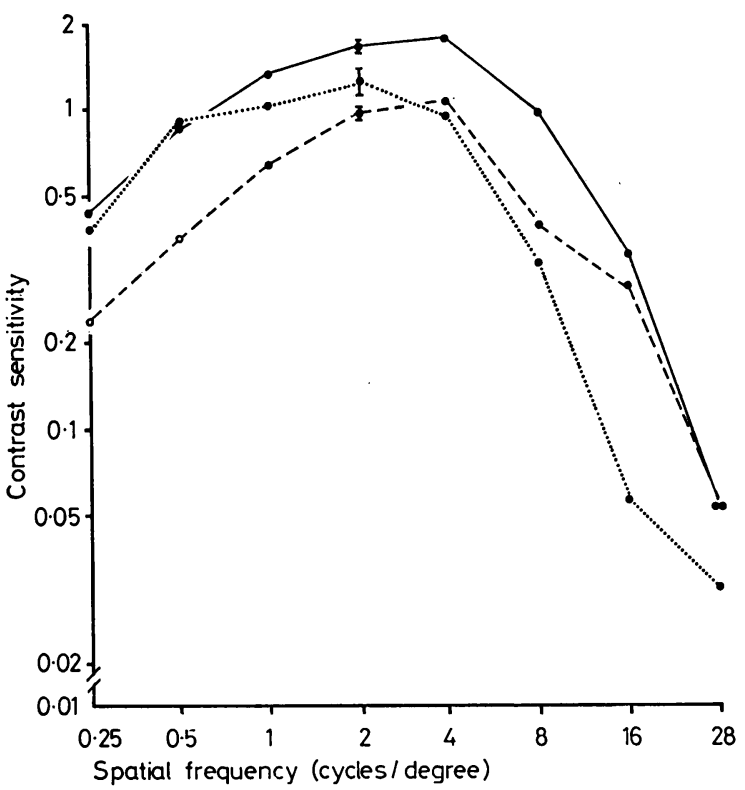

Fig. 1 Averaged contrast sensitivity functions for normal observers in 3 age groups: (- - 8 to 15 years; (—) 18 to 39 years; and (……) 45 to 66 years. The vertical bars indicate \pm the standard error of the mean

maximum and minimum luminances in the grating display respectively. Contrast sensitivity is the reciprocal of the contrast threshold.

The grating tests lasted approximately 20 minutes for each observer. Pupil diameter was measured during the course of the tests, and visual acuity was also measured by means of an internally illuminated Snellen letter chart, conforming to the British Standard 4274 (1968) and having a luminance of $270 \mathrm{~cd} / \mathrm{m}^{2}$.

\section{Results}

The averaged contrast sensitivity functions for those observers with normal vision are shown in Fig. 1. The observers were divided into groups according to whether they were at an age before physical maturation had been achieved or were at an age when presbyopia was likely. The curves for the younger (8 to 15 years) and middle-age (18 to 39 ) groups have a peak sensitivity at a spatial frequency of 4 cycles/degree, while the older group (45 to 66 years) peaks at 2 cycles/degree. All 3 curves are typically attenuated at low and high spatial frequencies. The younger group, with a mean Snellen acuity of $0.8(6 / 7 \cdot 5)$, demonstrates a somewhat lower sensitivity to low and mid spatial frequencies than the middle-age group, having a mean Snellen acuity of $1 \cdot 2(6 / 5)$. Both groups are essentially equal in their sensitivities to frequencies of 16 cycles/ degree and higher. The older group, with a mean Snellen acuity of $0.7(6 / 9)$, is less sensitive at mid and high frequencies than the middle age group and essentially equally sensitive to spatial frequencies of 0.5 cycles/degree and lower.

Fig. 2 shows the averaged contrast sensitivity functions for those observers suffering from bilateral diabetic retinopathy (mean Snellen acuity of 0.7 ) and for an observer with early lens opacities and

\begin{tabular}{llllll}
\hline $\begin{array}{l}\text { Age range } \\
\text { (years) }\end{array}$ & $\begin{array}{l}\text { Mean age } \\
\text { (years) }\end{array}$ & $\begin{array}{l}\text { Number of } \\
\text { eyes tested }\end{array}$ & $\begin{array}{l}\text { Mean } \\
\text { Snellen } \\
\text { acuity }\end{array}$ & $\begin{array}{l}\text { Mean pupil } \\
\text { diam (mm) }\end{array}$ \\
\hline$(---)$ & $8-66$ & 27 & 33 & $1 \cdot 1$ & 4.9 \\
$(--)$ & $31-55$ & 45 & 7 & $0 \cdot 7$ & 4.4 \\
$(\cdots \cdots)$. & 67 & 67 & 2 & 0.3 & 4.0 \\
\hline
\end{tabular}

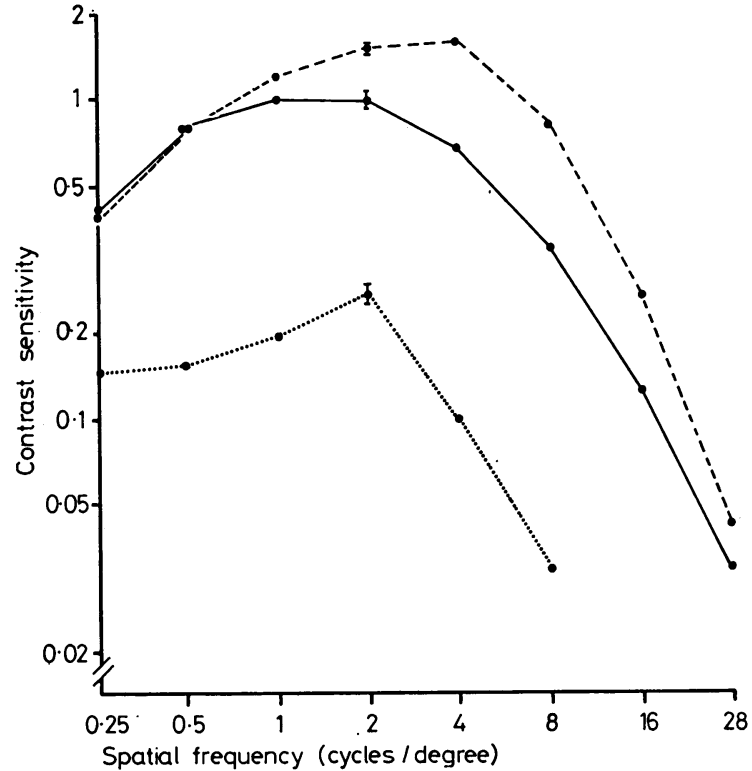

Fig. 2 Averaged contrast sensitivity functions for all normal observers $(---)$, those with bilateral diabetic retinopathy $(-)$ and 1 observer with early lens opacities and macular degeneration (…...). The vertical bars indicate \pm the standard error of the mean 
macular degeneration in both eyes (mean Snellen acuity of $0 \cdot 3(6 / 18)$ ). Compared to the average curve for all the normal observers the peak sensitivities of the curves for the 2 pathological conditions are shifted towards lower spatial frequencies. The diabetic curve shows a reduction in sensitivity to spatial frequencies of 1 cycle/degree and higher and the macular degeneration curve is markedly displaced towards low contrasts over the entire spatial frequency range.

\section{Discussion}

The contrast sensitivity function is a measure of both the optical and neural qualities of human vision, and changes of this function with age, such as those reported here, are to be expected. Variation of visual acuity with age is well known (Slataper, 1950), and the senile decrease in resolution is unlikely to be due to optical factors and the scattering of light within the eye alone; neural factors must be considered as well (Weale, 1975). Recently Mayer (1977) has reported that anisotropy, the greater visual sensitivity for horizontal and vertical gratings than for diagonal ones, increases with age from 5 to 11 years, and this can be attributed to neurological changes in the normally developing human visual system.

Deviations away from the normal contrast sensitivity curve in the case of observers with defective vision have also been reported by previous workers. Bodis-Wollner and Diamond (1976) have reported defects in the contrast sensitivity function of patients with cerebral lesions complaining of blurred vision. The scattering of light within the eye resulting from corneal oedema causes contrast sensitivity to be depressed for low and high frequencies (Hess and Garner, 1977). Contrast sensitivity is also depressed throughout the spatial frequency range in the case of anisometropic and strabismic amblyopia (Levi and Harwerth, 1977) and myopic amblyopia (Fiorentini and Maffei, 1976).

The author thanks Mr D. J. Faulkner, of the Institute of Ophthalmology, for designing the television grating generator used in this study; also the staff and patients of Moorfields Eye Hospital and the London Refraction Hospital who acted as observers. The author is particularly grateful to Messrs H. A. Vallis and R. Llewellyn, of the London Refraction Hospital, for their help in obtaining observers and for providing a room in which to perform the experiments. During the duration of this work the author was in receipt of a research studentship from the Medical Research Council.

\section{References}

Bodis-Wollner, I., and Diamond, S. P. (1976). The measurement of spatial contrast sensitivity in cases of blurred vision associated with cerebral lesions. Brain, 99 695-710.

Campbell, F. W., and Green, D. G. (1965). Optical and retinal factors affecting visual resolution. Journal of Physiology, 181, 576-593.

Fiorentini, A., and Maffei, L. (1976). Spatial contrast sensitivity of myopic subjects. Vision Research, 16, 437-438.

Hess, R. F., and Garner, L. F. (1977). The effect of corneal oedema on visual function. Investigative Ophthalmology and Visual Science, 16, 5-13.

Levi, D. M., and Harwerth, R. S. (1977). Spatio-temporal interactions in anisometropic and strabismic amblyopia. Investigative Ophthalmology and Visual Science, 16, 90-95.

Mayer, M. J. (1977). Development of anisotropy in late childhood. Vision Research, 17, 703-710.

Schade, O. H. (1956). Optical and photoelectric analog of the eye. Journal of the Optical Society of America, 46, 721-739.

Slataper, F. J. (1950). Age norms of refraction and vision. Archives of Ophthalmology, 43, 466-481.

Weale, R. A. (1975). Senile changes in visual acuity. Transactions of the Ophthalmological Societies of the United Kingdom, 95, 36-38. 